\title{
Conducting High Cycle Fatigue Strength Step Tests on Gamma TiAl
}

\author{
B.A. Lerch, S.L. Draper, and J.M. Pereira \\ NASA-Glenn Research Center \\ Cleveland, $\mathrm{OH} 44135$
}

Keywords: Intermetallic, Titanium, Coaxing, Fatigue, High Temperature

\begin{abstract}
High cycle fatigue strength testing of gamma TiAl by the step test method is investigated. A design of experiments was implemented to determine if the coaxing effect occurred during testing. Since coaxing was not observed, step testing was deemed a suitable method to define the fatigue strength at $10^{6}$ cycles.
\end{abstract}

\section{$\underline{\text { Introduction }}$}

The recent emergence of gamma TiAl has prompted much interest in this material as a lightweight alternative for turbine blades [1]. This has incited numerous fatigue studies of this intermetallic alloy system. The S-N curve is relatively flat $[2,3,4]$ and at least two alloys exhibit a horizontal S-N curve $[2,3]$, thus leading to run-outs ${ }^{1}$ and potentially long and expensive testing times. The selection of an appropriate stress level for conducting a test is exacerbated by inherent variability in material strength. Thus, populating an S-N curve is difficult. To overcome this problem, a step test approach [5] has been adopted, in which the sample is cycled at a stress low enough to insure that a run-out occurs. The applied stress is then increased by a small increment and cycling continues. If the test is run-out at this stress level, then another load increase is applied. This process continues until the sample finally fails. The point on the S-N curve is given as the final stress where failure occurred, and the number of cycles to failure at this stress level. This type of test forces every sample to fail and produces a more thoroughly populated S-N curve.

\footnotetext{
${ }^{1}$ A run-out is a test which has not failed by a predetermined cycle, normally $10^{6}$ cycles or longer.
} journal for publication. Because of changes that lay be made before formal publication, this reprint is made available with the understanding reprint is made available with the understand wing ermission of the author 
The potential use of low ductility $(<2 \%)$ TiAl as a blade material has caused concerns about its ability to withstand impact damage and ensue catastrophic failure. Even if an impact is survived, the cyclic crack growth resistance may not be sufficient to avoid eventual fatigue failure before the next inspection interval. For the above reasons, the damage tolerance of TiAl has recently been investigated. Damage has been introduced by either statically indenting the sample with wedges $[2,6]$, or by ballistically impacting a sample with projectiles $[7,8,9]$. Samples are then fatigued using the step test procedure. The necessity of running step tests is enhanced by the impact damage because of the uncertainty of the size and severity of the damage zone, and the resulting failure stress of the sample. If the fatigue stress level is chosen too high, the sample breaks immediately and is an invalid test since it is not clear if the sample would have failed at even lower stress levels. So the tendency is to be ultra-conservative and start with a very low starting stress resulting in a run-out, but then incrementally "sneaking up" on the failure stress with subsequent steps. For these tests the fatigue strength at a specific cycle number $\left(10^{5}\right.$ $-10^{7}$ ) is used to calculate the stress intensity factor for the original flaw size. An S-N curve is not usually generated.

As early as the 1930's, it was shown that step testing led to artificially high fatigue limit strengths in steels compared to using conventional single level stress testing [10]. This behavior was termed coaxing. Coaxing is not observed in all materials, but has been observed in iron [10], steels $[10,11,12]$ and molybdenum [13]. Several reasons for coaxing have been postulated, the primary explanation being a strain aging phenomenon $[10,12,14,15]$. Coaxing has been rumored amongst researchers who have tested gamma, although to the authors' knowledge this has never been proven. Previous work by the authors on the cast gamma alloy 48-2-2 has produced data suggesting a coaxing effect. Figure 1 shows the fatigue failure strength at $10^{6}$ cycles determined by step testing as a function of defect size. Defect size is the crack length due to either the ballistic impact or

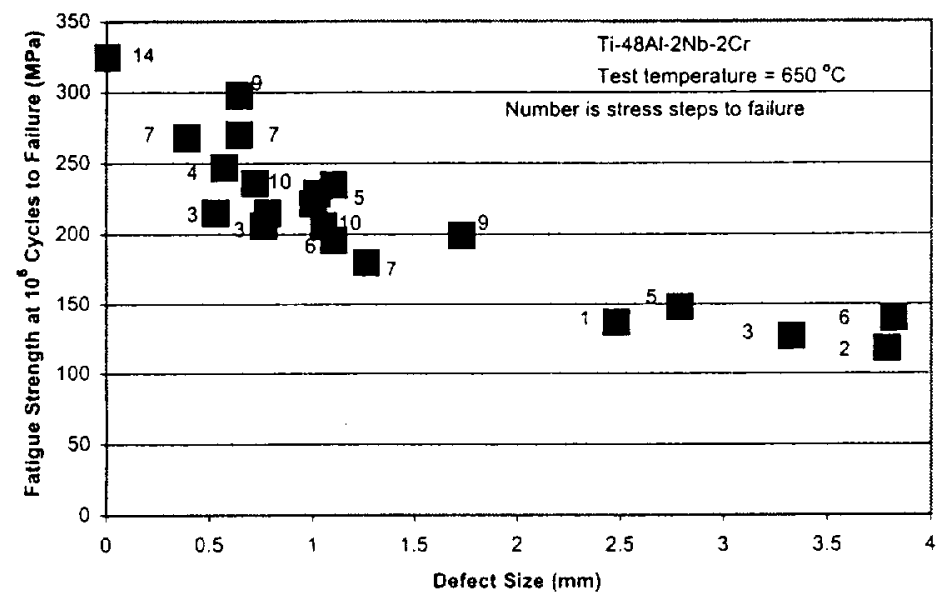

Figure 1 Fatigue strength at $10^{6}$ cycles to failure as a function of defect size from either impact cracks or casting porosity. 
other inherent defects (such as porosity) in the material. As expected the failure strength decreases with increasing crack size. In this figure the number of stress increments (steps) until failure are indicated next to the data points. For a given defect size, those samples with higher failure strengths generally required more steps (see in particular those points at approximately $0.6 \mathrm{~mm}$ defect size). This effect appears to be more significant at smaller defect sizes and diminishes as the defect becomes larger. The coaxing phenomenon, if it occurs in gamma alloys, would render the results meaningless for design. Consequently, this paper addresses whether or not the relationship between the number of steps and the failure strength is a result of coaxing.

\section{Experimental Procedure}

Ti-46.4Al-1.8Cr-1.8Nb-0.180 (at. \%) slabs were cast by Howmet Research Corp. (Whitehall, MI) and processed in a typical sequence, including heat treatment at $1093{ }^{\circ} \mathrm{C}$ for $5 \mathrm{~h}$ followed by hot isostatic pressing at $1185^{\circ} \mathrm{C} / 172 \mathrm{MPa}$ for $3 \mathrm{~h}$. All fatigue samples were machined from one slab into flat dogbones, $15 \mathrm{~cm}$ in length. The straight gage section was $26 \mathrm{~mm}$ long by $10 \mathrm{~mm}$ wide and $2.2 \mathrm{~mm}$ thick. The gage had an elliptical cross-section, designed to simulate the leading edge of a low pressure turbine (LPT) blade.

Samples were cycled at $650^{\circ} \mathrm{C}$, a frequency of $80 \mathrm{~Hz}$ and a stress ratio $\left(\sigma_{\min } \backslash \sigma_{\max }\right)$ of 0.05 . If the samples did not fail after $10^{6}$ cycles, the maximum stress was increased by approximately $14 \mathrm{MPa}$ and the sample cycled for another $10^{6}$ cycles. This process was repeated until the sample separated into two pieces.

Tests were run on both virgin (non-impacted) and impacted samples. For impacting, the sample was heated to $260^{\circ} \mathrm{C}$ and a $70 \mathrm{MPa}$ tensile stress was applied. Impacting was performed using a gas gun firing a $1.6 \mathrm{~mm}$ steel ball at the sample. The hardness of the ball was $\leq 20$ HRC. The projectile speed was approximately $120 \mathrm{~m} / \mathrm{s}$, which yielded an impact energy of $0.12 \mathrm{~J}$. The sample was impacted at a location $0.5 \mathrm{~mm}$ from the edge and parallel to the thickness of the sample. The resulting surface cracks were measured before fatigue testing. Further details on testing can be found in [7].

\section{Design of Experiments (DOE)}

To investigate the step test method, a series of fatigue tests were run on virgin samples at $650^{\circ} \mathrm{C}$ in air. This was done since the undamaged samples should all fail at nominally the same stress, simplifying the choice of a starting stress level. Also based on figure 1, the effect of the number of steps should be largest for the undamaged samples. A few preliminary tests identified the failure strength as approximately $300 \mathrm{MPa}$. The remaining specimens were divided into two groups; starting stress levels of $214 \mathrm{MPa}$ and $280 \mathrm{MPa}$. The first group would require more stress step levels to reach the expected failure strength of $300 \mathrm{MPa}$. If coaxing occurred, these samples would have a higher failure strength. 
A limited number of specimens were also available to study the effect of step testing on impacted samples. Impact conditions were chosen such that the resulting damage was small and would show the largest possible coaxing effect per the results in Figure 1.

To properly resolve any influence of coaxing, the following calculations were made to determine the required sample size. It was decided that a minimum of a $15 \%$ increase above the constant amplitude fatigue strength would have to be observed to be called coaxing. A difference of only $10 \%$ is decidedly too small and would be indistinguishable from normal fatigue scatter. Any difference larger than $15 \%$ would be discernable with a smaller sample size. Based on six preliminary tests using various starting stresses, a standard deviation in fatigue strength was calculated to be $23 \mathrm{MPa}$. Assuming both $\alpha$ and $\beta$ errors (i.e., the probability of erroneously rejecting or accepting a hypothesis, respectively) of 0.05 , the estimated required sample size was calculated by:

$t\left(0.975 ; N_{1}+N_{2}-2\right)+t\left(0.95 ; N_{1}+N_{2}-2\right) * \sqrt{\frac{1}{N_{1}}+\frac{1}{N_{2}}}=\frac{\delta}{S_{p}}$

where $t$ is the $t$-distribution, $N_{1}$ and $N_{2}$ are the sample sizes for each starting stress level, $\delta$ is the observed difference ( $15 \%$ ), which we wish to observe above the conventional fatigue strength, and $S_{p}$ is the standard deviation. This yielded a required sample size of

8 per starting stress level. If the actual standard deviation were larger than $23 \mathrm{MPa}$, more samples would be required to discern a $\delta$ of $15 \%$.

\section{Results and Discussion}

Fatigue test data are shown in Table I. Eight samples were started at approximately 214 $\mathrm{MPa}$ and 9 samples at $280 \mathrm{MPa}$. The fatigue strength is the maximum stress at which the specimen survived $10^{6}$ cycles. The stress steps include the final increment.

Table I is ordered for each starting stress by the number of stress steps to failure. There is an excellent correlation between the number of steps and the fatigue strength - the higher the fatigue strength, the more steps. Exactly for this reason, this investigation was conducted.

The means and standard deviations of the two groups of virgin samples were compared using an analysis of variance. For the group started at a stress level of $214 \mathrm{MPa}$ the mean and standard deviation were 318 and $21 \mathrm{MPa}$, respectively. For a starting stress of 280 MPa the mean and standard deviation were 327 and $11 \mathrm{MPa}$. The hypothesis that the means (and standard deviations) were significantly different was rejected at the $95 \%$ confidence level. Thus, whether the step tests were started at low or high stress levels made no difference to the fatigue strength. Hence both means were pooled to give a average fatigue strength of $323 \mathrm{MPa}$. It should be mentioned that the pooled standard deviation on the mean was $16 \mathrm{MPa}$, less than the preliminary value of $23 \mathrm{MPa}$ used to calculate the required sample size. Thus, the power of the test was more than sufficient to discern a difference of $15 \%$ had it existed. 
Table I - Fatigue Results from DOE

\begin{tabular}{|c|c|c|c|}
\hline Specimen & $\begin{array}{c}\text { Starting } \\
\text { Stress } \\
(\mathrm{MPa})\end{array}$ & $\begin{array}{c}\text { Fatigue } \\
\text { Strength } \\
\text { (MPa) }\end{array}$ & $\begin{array}{c}\text { Stress } \\
\text { Steps }\end{array}$ \\
\hline $2-3-5$ & 211 & 281 & 6 \\
\hline $2-3-1$ & 217 & 304 & 7 \\
\hline $2-3-14$ & 214 & 307 & 8 \\
\hline $2-3-16$ & 214 & 321 & 8 \\
\hline $2-3-26$ & 214 & 320 & 9 \\
\hline $2-3-23$ & 214 & 331 & 10 \\
\hline $2-3-29$ & 214 & 335 & 10 \\
\hline $2-3-3$ & 217 & 348 & 10 \\
\hline $2-3-12$ & 280 & 308 & 3 \\
\hline $2-3-2$ & 286 & 315 & 3 \\
\hline $2-3-19$ & 280 & 321 & 4 \\
\hline $2-3-30$ & 280 & 321 & 4 \\
\hline $2-3-24$ & 280 & 333 & 4 \\
\hline $2-3-15$ & 280 & 333 & 5 \\
\hline $2-3-35$ & 280 & 333 & 5 \\
\hline $2-3-22$ & 280 & 338 & 5 \\
\hline $2-3-27$ & 280 & 340 & 5 \\
\hline \multicolumn{5}{|c|}{ Impacted } \\
\hline $2-3-31$ & 107 & 268 & 13 \\
\hline $2-3-9$ & 221 & 290 & 6 \\
\hline \multicolumn{5}{|c|}{}
\end{tabular}

The higher fatigue strength observed when more steps are used is simply due to natural material scatter and not due to coaxing. In other words, given a starting stress, a slightly stronger specimen requires more steps to fail.

\section{Impacted Samples}

Six samples were available for impacting and the subsequent study of step testing. The same nominal impact conditions were used on each sample. Impacting produced a backside crack $^{2}$ on each sample between 0.6 and $1 \mathrm{~mm}$ in length. This large variation in impacted crack length is undesirable for planning fatigue tests, but is typical of

this type of testing for TiAl. This scatter makes it difficult to appropriately choose a starting stress level for the fatigue tests.

Of the 6 impacted samples, only two of the samples actually failed at the backside crack. The other four samples failed elsewhere in the gage section, indicating the good damage tolerance of this material. Of the two samples failing at the impact damage, specimen 2 3-31 had a slightly smaller crack, was started at a lower stress, and required more stress steps to failure. This sample had a lower fatigue strength than the other sample (2-3-9), which again suggests that coaxing is not an issue.

The remaining impacted samples (not listed in Table I) were treated as virgin samples since they did not break at the impact. Their average fatigue strength was $310 \mathrm{MPa}$ and falls within the $95 \%$ confidence interval of the pooled means calculated previously from the DOE. Note that since these tests were expected to fail at lower stress values due to the impact damage, they were all started at very low stress levels. Hence, they required a large number of steps (10-17) for failure. This is another indication that coaxing did not occur.

\footnotetext{
${ }^{2}$ A backside crack is a semi-elliptically shaped crack, perpendicular to the load axis on the sample. It forms on the backside of the sample opposite from the impact. More details on these cracks can be found in reference 7 .
} 


\section{Conclusions}

This study shows that coaxing does not occur during fatigue step testing of cast gamma TiAl. Any apparent coaxing is due to inherent material scatter and the method of conducting the test. Step testing is a viable procedure for determining the fatigue strength of virgin samples, as well as to assess the robustness of the material to impact damage.

\section{Acknowledgments}

This work was supported by NASA's Ultrasafe Program. The authors thank Ralph Corner for his technical support conducting the fatigue tests.

\section{References}

1. C.M. Austin, T.J. Kelly, K.E. McAllister and J.C. Chesnut, Structural Intermetallics 1997, TMS, Warrendale, PA, 1997, pp. 413-425.

2. T.S. Harding and J.W. Jones, Scripta Materialia, Vol. 43, 2000, pp. 623-629.

3. J. Kumpfert, Y.W. Kim, D.M. Dimiduk, Mat. Sci. and Eng., A192/193, 1995, pp. 465-473.

4. V. Recina and B. Karlsson, Scripta Materialia, Vol. 43, 2000, pp. 609-615.

5. A.F. Madayag, Metal Fatigue: Theory and Design, John Wiley and Sons, NY, 1969, pp. 144-148.

6. T.S. Harding and J.W. Jones, Met. Trans., Vol. 31 A, 2000, pp. 1741-1752.

7. S.L. Draper, B.A. Lerch, J.M. Pereira, M.V. Nathal, C.M. Austin and O. Erdman, Met. Trans., Vol. 32A, 2001, pp. 1-16.

8. R. Smith, T. Harding, J.W. Jones, P. Steif and T.M. Pollock, Structural Intermetallics 2001, TMS, Warrendale, PA, 2001, pp. 259-268.

9. T.S. Harding and J.W. Jones, Scripta Materialia, Vol. 43, 2000, pp. 631-636.

10. G.M. Sinclair, Proc. ASTM, Vol. 52, 1952, pp. 743-758.

11. J.B. Kommers, Poc. ASTM, Vol. 38, Part II, 1939, pp. 249-268.

12. J.C. Levy and S.L. Kanitkar, J. of Iron and Steel Institute, 1961, pp. 296-300.

13. R.I. Stephens, R.G. Dubensky, L.L. Frauen and R.L. Wrenn, J. of Materials, JMLSA, Vol. 7, No. 1, 1972, pp. 64-70.

14. T. Nakagawa and Y. Ikai, Fatigue of Engineering Materials and Structures, Vol. 2, 1979, pp. 13-21.

15. V.I. Belyaev, Problems of Metal Fatigue, Daniel Davey and Co., Inc., 1963, pp. 1738. 